\title{
DOENÇA PROFISSIONAL POR AGENTE BIOLÓGICO EM DENTISTA
}

\author{
Diogo) Pupo Nogueira*
}

NOGUEIRA. D. P. Duenca profissional nor asente biológico enı dentista. Rev. Saúde públ., S. Paulu, 16:303-6, 1982 .

RESCMO: E apreséntado um caso de infecção luética cutànes de dedo de dentista, com a lesão primária surgindo no local onde pré-existia falta de continuidade da pele em decorrência de acidente do trabalho de pequena gravidade. faita a descrição do estudo epidemiológico levado a efeito entre clientes do dentista, que levou à idertificação do paciente infectante.

INITERMOS: Doenças profissionais. Dentistas.

\section{INTRODUCÃO}

A profissão de dentista implica reconhecidamente en diversos riscos ocupacionais. Assim, Vendroux ${ }^{+}$assinala que, ao lado dos acidentes de trabalho representados, na sua maioria, por cortes e abrasóes dos ciedos, há a possibilidade da ocorrência de diversas doenças profissionais por agentes físicos, mecànicos e biológicos; causa principal destes é a inalação do aerosol provocado pela água de resfriamento das brocas de alta rotação que, em contato com a boca do paciente, podem transferir deste para o profissional, germes patogênicos diversos, alguns de alto risco.

No entanto, além dos riscos biológicos decorrentes da inalação de tais aerosóis, há a possibilidade de outros, menos conhecidos, que poden ser transmitidos ao dentista por via transcutânea. Trata-se de um tipo relativamente raro de duença profissional; assim, um levantamento feito pelo "Centre International d'Informations" (CIS) da Organização Internacional do Trabalho, a partir de dados acumulados no seu centro de computação, não referte sequel un desses casos.

Uma das razóes de que esise tipo de doença profissional seja tão raramente observado é que o controle da saude dos dentistas não é feito, geralmente, de forma sistemática, pelo qual muitos desses episódios passam despercebidos pelos próprios profissionais ou não são levados ao conhecimento da coletividade científica por talta de meios de informação.

As empresas industriais nas quais existe serviço de saúde e segurança ocupacionais bem desenvolvido oferecem condições ideais para a observaçāo desse raro tipo de doença profissional. Trata-se de uma comunidade lechada, que é perfeitamente controlada no

\footnotetext{
* Do Departamento de Saúde Ocupacional da Faculdade de Saúde Pública da USP - Av. Dr. Arnaldo. 715 - 01255 - São Paulo, SP - Brasil.
} 
NOGUEIRA, D.P. Doença profissional por agente blológico em dentista. Rev. Saúde públ., $\mathbf{S}$. Paulo, 16:303-6, 1982.

que respeita à saúde dos seus membros e cnde estudos epidemiológicos podem ser levados a cabo com a maior facilidade.

Foi julgado de interesse, portanto, descrever um caso de doença profissional extremamente raro e de mostrar quais os procedi. mentos epidemiológicos que, a partir de sua descoberta, tiveram que ser adotados.

\section{RELATO DO CASO}

Em 1977, um dentista de empresa industrial da Capital do Estado de São Paulo, que dispōe de um bem estruturado serviço especializado de segurança e medicina do trabalho na forma estabelecida por lei 2 ao abrir uma caixa de medicamentos, sofreu pequeno acidente do trabalho, com ferimento cortante insignificante da segunda falange do indicador direito; tal ferimento sofreu simples assepsia e não recebeu nenhuma proteção, dadas as suas minimas proporçöes, e o dentista continuou a sua atividade profissional sem maiores problemas. $O$ ferimento cicatrizou-se por primeira intenção nos dias seguintes, pelo que o profissional não mais deu a ele qualquer importância.

Cerca de 10-12 dias depois do acidente do trabalho, o profissional notou o aparecimento, no local da lesão primitiva, de ulceração indolor, de bordos ligeiramente endurecidos, que aumentou progressivamente de tamanho, atingindo cerca de 5 milimetros de diâmetro. Como o tratamento local com pomadas antisséticas fosse inútil, foi $o$ profissional visto por dermatologista, que não diagnosticou a etiologia da ulceração e que prescreveu pomadas a base de corticosteróides. O profissional continuou trabalhando sem utilizar curativo local, visto que este interferia com a boa higienização das mãos. A ulceração evoluiu durante aproximadamente 10 dias e desapareceu sem deixar cicatriz.

Cerca de um mès após o desaparecimento da ulceração, notou o profissional o aparecimento de exantema cutâneo, aproximada- mente simétrico, não pruriginoso, que tomava todo o corpo, inclusive palma das mãos. Submetido a exame médico e en vista dos característicos de roséola sifilitica, foram solicitadas soro-reações para a lues, que se mostraram altamente positivas. Foi imediatamente instalado o tratamento com penicilina, nas doses usuais para essa moléstia, do que resultou a cura completa.

\section{CONSIDERAÇOES EPIDEMIOLÓGICAS}

O estudo retrospectivo do caso evidenciava, sem sombra de dúvida, que o dentista tinha adquirido a infecção sifilitica pelo contato do pequeno ferimento do dedo com a mucosa bucal de um paciente portador de sifilis, caracterizando-se uma doença profissional por agente biológico. Em vista disso, havia urgente necessidade de que a população atendida pelo profissional no periodo entre a ocorrência do ferimento $e$ o desaparecimento da lesão sifilítica primária do dedo fosse submetida a soro-reaçōes para a lues com um duplo objetivo, a saber:

1. Identificar o doente infectante, com o objetivo de evitar o risco de disseminar a doença e de curar a sifilis que apresentava.

2. Verificar se a lesão do dedo do dentista, enquanto permaneceu aberta, não teria infectado outros pacientes não doentes, por ele tratados.

O fato da população de uma organização industrial ser relativamente estável e bem conhecida facilitava muito tal estado epidemiológico. Assim, primeiramente foi feito o levantamento de todos os pacientes que tinham sido atendidos pelo dentista, desde o dia da ocorrência do acidente do trabalho até a data em que a lesão do dedo tinha se cicatrizado inteiramente; tal levantamento foi facilmente feito através do fichário do consultório dentário.

Uma vez feito o levantamento, todos os pacientes listados foram chamados e subme- 
NOGUEIRA, D.P. Doença profissional por agento biológico em dentista. Rev. Saúde puibl., S. Paulo, 16:303-6, 1982.

tidos a soro-reações para a lues. Apenas em um caso os resultados foram positivos: tratava-se do paciente que tinha sido atendido exatamente no dia do acidente e que apresentava soro-reações para a lues altamente positivas; em todos os demais casos os resultados foram negativos. $O$ paciente com resultados positivos foi submetido a tratamento com penicilina, nas doses usuais, com cura completa.

\section{COMENTÄRIOS}

As lesões primárias sifiliticas de localização extra-genital eram bastante frequientes na era pré-antibióticos. Rosenau ", em 1935, citando trabalhos de Bulkly e de Munchermer e Fournier, informa que em 20.000 casos de lesões extra-genitais, $897 \quad(4,48 \%)$ forám observados em dedos e mão de médicos, enfermeiros e parteiras; nenhum caso de infecção em dentista é citado.

A revisão bibliográfica solicitada ao CIS não revela nenhum caso de infecção de dentista. Mesmo Vendroux ${ }^{+}$, ao estudar especificamente o problema de cortes e abrasões de dedos de dentistas, não refere o risco de doença profissional por agente biológico. Dessa forma, a descrição do caso presente, pela sua raridade, parece justificar a sua publicação, principalmente como alerta aos dentistas sobre um risco pouco conhecido de sua profissão.

Como medidas preventivas, o uso de luvas cirúrgicas é impraticável, pois a experiência mostra que são rarissimos os profissionais de odontologia capazes de executar suas atividades profissionais utilizando esse equipamento de proteção individual. O dentista, cujo caso é relatado, sensibilizado pela ocorrência da doença e tendo o máximo interesse em se proteger contra o aparecimento de outra infecçção, não conseguiu utilizar o Equipamento de Proteçāo Individual (EPI), sendo obrigado a abandoná-lo ao cabo de dois meses de experiência.

A única medida preventiva teoricamente eficaz seria a suspensão do trabalho odontológico sempre que ocorra lesão de mãos e dedos; no entanto, tal medida teria reflexos sobre a atividade laborativa do profissional, pelo que na prática teria pouca aplicação.

Medida preventiva alternativa seria a cobertura dos ferimentos de mãos e dedos com curativos hermeticamente fechados, passiveis de serem lavados toda a vez yque o profissional odontólogo lava as mãos e que não pudessem transferir de um paciente para outro infecçóes eventualmente existentes. Estudos nesse sentido seriam altamente aconselháveis.

O caso descrito ainda mostra a facilidade que uma comunidade industrial oferece para estudos epidemiológicos. Comunidade fechada, com fácil acesso aos seus membros, oferece condições ideais para estudos dessa natureza, ao contrário das comunidades abertas, onde o acesso aos seus componentes nem sempre é fácil. Essas peculiaridades da comunidade industrial permitiram, no caso presente, a fácil identificação do portador da infecção; por outro lado, permitiu que se tivesse a possibilidade de investigar a possivel infecção de outros membros da comunidade pelo próprio odontólogo infectado, e que neste caso não ocorreu. Assim, dentro daqueles princípios descritos por Newhouse e Schilling ${ }^{1}$, foi possivel un controle altamente eficiente da população exposta e a solução do problema através de tratamento adequado do empregado que, desconhecendo o seu estado de saúde, constituia um risco para seus companheiros de trabalho e, evidentemente, para a comunidade em geral. 
NOGUEIRA, D.P. Doença profissional por agente biológico em dentista. Rev. Saúde públ., S. Paulo, 16:303-6, 1982 .

NOGUEIRA, D. P. [Professional infection by biological agent in a dentist]. Rev. Saúde públ., S. Paulo, 16:308-6, 1982.

ABSTRACT: A case of a primary lesion of syphillitic origin appearing in a previously cut finger of a dentist is described, as well as the epidemiological procedure taken to identify the patient who was the infectant.

UNITERMS: Occupational diseases, Dentists.

\section{REFERẼNCIAS BIBLIOGRÁFICAS}

1. NEWHOUSE, M.L. \& SCHILLING, R.S.F. Uses and methods of epidemiology. In: Schilling, R.S.F. Occupational health practice. London, Butterworths. 1973. p. 169-89.

2. PORTARIA 3.214, de 8 de junho de 1978. In: Campanhole, A. \& Campanhole, H.L. Consolidação das leis do trabalho $e$ legislação complementar. $51^{\text {* ed. São }}$ Paulo, Atlas. 1979. p. 696-735.
3. ROSENAU, M.J. Preventive medicine and hygiene. 6 th ed. New York, Appleton-Century, 1935. p. 447.

4. VENDROUX, C. Dentists. In: Encyclopaedia of occupational health and safety. Geneva, International Labour Office. 1972. v. 1, p. $371-2$.

Recebido para publicação em 29/01/1982

Aprovado para publicação em 28/06/1982 